Opinion Survey, 1964." Department of Political Science, University of California, Los Angeles, 1964 (ditto).

10. The Survey Research Centre data were made available by the InterUniversity Consortium for Political Research. Neither the Survey Research Centre nor the Consortium, of course, bear any responsibility for the analyses or interpretations presented here.

11. A somewhat related experiment has been carried out by Norman Miller using two groups of high school students-one strongly favourable to fluoridation, the other strongly opposed. Members of each group were presented arguments antagonistic to their own position. Controlling for dogmatism in the subjects and under varying degrees of involvement introduced by the experimenter, it was found in all cases

- that proponents were far more likely to alter their position when confronted with the uncongenial arguments than were the opponents. Miller suggests that con subjects were perhaps simply psychologically less persuadable, a conclusion which is certainly plausible given his method for choosing subjects. He is inclined to dismiss the argument that the pro and con communications were different in persuasive strength on the rather unimpressive grounds that the communications in his experiment were comparable in "type, number, and delivery." As far as the present study is concerned, proponents were, if anything, slightly less persuadable than opponents judging from responses to the questions enumerated in Table 3. "Involvement and Dogmatism as Inhibitors of Attitude Change." J. Exper. Psychol. 1:121-132 (May), 1965.

\title{
Commentary on "Fluoridation Attitude Change"
}

By William A. Gamson, PH.D.

Department of Sociology, University of Michigan, U.S.A.

Professor Mueller's study of the impact of exposure to pro- and antifluoridation arguments adds considerable support to the speculation of many who have witnessed the difficulties encountered by fluoridation proponents in referenda. A variety of indirect evidence has lent sustenance to this speculation, but Mueller is the first to confront the question directly. The results are likely to be discouraging for proponents of fluoridation and may even raise some doubts in their own minds. Is there some genuine merit in antifluoridation arguments which some disinterested people are able to see when presented with both sides?

Perhaps, but one can gain some perspective on these results by viewing them in a more general light. On any political issue, those on one side are likely to have a "natural advantage" over those on the other side, an advantage which will enable them to win if they simply hold their own in an influence contest. This natural advantage falls to those who do not carry the burden of proof. In relatively stable, nonrevolutionary situations, this advantage is held by those who would maintain a present arrangement against those who would alter it. Many community issues arise from the presentation of a proposal to alter some existing facility or service or to add some new facility. The burden of proof in such cases generally rests with the side proposing the change. For example, if a new school is proposed, those who oppose it may raise any number of questions about need, cost, design, site, and so forth. It is not necessary to resolve such questions in order to block action on this proposal; if they remain unanswered, this is generally sufficient. 
There is some firm evidence for this argument in a study of 54 issues in 18 New England communities.* Measures were taken of the size of the campaign effort by the side advocating some change and by the side supporting the status quo. In almost two-thirds of the cases in which the side supporting change won, they made a greater campaign effort than the other side. However, when the side supporting no change won, they made a greater effort only a third of the time; twothirds of the time they were able to win with no more effort than the losing side.

If the above argument is valid, fluoridation proponents are no - different from other change advocates. Mueller's results should be replicated for any controversial change, that is, on any proposed change for which there is an active opposition. It would be helpful, in Mueller's study, to know the characteristics of those people who were most susceptible to influence by opposition arguments. One would hypothesise that they are little informed about and interested in fluoridation, supporting it out of general faith in the benevolence of the Public Health Service and other organisations which advocate this public health measure. Such vague and general support is vulnerable to opposition arguments, and proponents of fluoridation would be wise to recognise that their mass support is less stable than the opponents' mass support and, consequently, that they are likely to be at a disadvantage in any prolonged referendum campaign.

\section{Reply by Dr. Mueller}

Professor Gamson's point is a sound one. While the purpose of the experiment was to show that neither skilled agitation nor conspiratorial argumentation about the "structure of authority" are necessarily essential to alter attitudes on fluoridation away from the favourable pole, the generality of this finding is well worth looking into. At the same time, it should be noted that the phenomenon cited in the experiment is likely to be stronger in the fluoridation case than on other issues.

For one thing, the very admission that there is disagreement on the issue, that "doctors disagree," is enough to cause many to join the antifuoridation camp. The public seems to demand unanimity of professional opinion on this issue, but on a school bond issue, for example, the mere existence of debate is not so likely to have such an important effect. Additionally, water fluoridation has not proved to be subject to compromise. Alternative methods of mass distribution have generally been rejected as unworkable, dangerous, or both. Thus, opposition cannot be partly undercut in advance by reducing the demand-as a proposal to substitute a modest school building programme for a large one can sometimes satisfy moderate opponents. It might also be noted that a somewhat similar procedure was used in other parts of the experiment to probe the resilience of civil liberties attitudes. It was found that argumentation altered attitudes on this issue very little.

* Reported in Gamson, William A. Reputation and Resources in Community Politics. Am. J. Sociol. 72:121-131 (Sept.), 1966. 